\title{
KAP Study Regarding the Oral Health
}

\author{
Attika Batool ${ }^{1}$, Fozia Khanam², Efra Sikandar ${ }^{3}$ \\ 1. House Offer Dental Section Allied Hospital, Faisalabad \\ 2. Senior Medical Officer Fatima Jinnah Hospital, Multan \\ 3. Woman Medical Officer THQ Hospital Sillanwali
}

\begin{abstract}
:
Objective: To assess the knowledge, attitudes and practice regarding the oral health in our community. Study Design: Cross Sectional Study. Study Place and Study Duration: from January 2016 to June 2018, in Dental Section Allied Hospital, Faisalabad, Fatima Jinnah Hospital, Multan and THQ Sillanwali. Material and methods: A total number of 378 patients were enrolled in this study. A questionnaire was developed to gather the information required for the determination of knowledge, attitudes and behavior of the patient towards oral health. The questionnaire comprised of thirty three questions regarding different aspects of oral health care. It involved questions regarding demographic information, knowledge, attitudes and behavior of the patients. Results: Regarding oral care, $\mathrm{n}=213(56.3 \%)$ used tooth paste, $\mathrm{n}=260(68.8 \%)$ patients brush once a day, $\mathrm{n}=178(47.1 \%)$ used vertical technique for brushing. $\mathrm{n}=138(36.5 \%)$ changed their brush every six months while $\mathrm{n}=60(15.9 \%)$ changed their brush after one year. $\mathrm{n}=189(50 \%)$ patients brush their teeth in morning, $\mathrm{n}=166(43.9 \%)$ brush their teeth for cleaning purpose. $n=144(38.1 \%)$ visited to dentist when they felt pain. $n=170(45 \%)$ ignore, $n=98$ $(25.9 \%)$ go to the dentist and $\mathrm{n}=110(29.1 \%)$ use home remedies when they felt dental decay. $\mathrm{n}=239(63.2 \%)$ patients' family members brush their teeth regularly. Self-medication was observed as $n=269(71.2 \%)$. Conclusion: Although majority of the patients had good knowledge about health care but it was not associated with better attitudes, behavior and practicing of healthy habits. It can be suggested that poor socioeconomic conditions of majority of the public and lack of motivation for oral hygiene are the cause of poor behavior, attitude and practicing of dental care.
\end{abstract}

Keywords: Knowledge, Attitudes, Behavior, Oral Health

DOI: $10.7176 / \mathrm{JMPB} / 52-14$

\section{Introduction:}

In recent years a considerable reduction in incidence and severity of oral diseases has been observed especially in developed countries ${ }^{1}$. A systemic and organized dental care has been employed to improve the oral health in children and young adults ${ }^{2,3}$. As a result of this systemically organized way of oral health care there has been significant decline in the frequency of dental caries in patients ${ }^{4}$. Another advantage of this mode of health care is that, an increased number of adults are now able to keep their original denture for later stages of the life (5). But it has only improved overall dental health in developed countries unlike in developing countries where dental care is still one of the major health problems ${ }^{6}$.

The reasons behind the improvement in overall dental health in developed and industrialized countries are the life style modifications, improved self care practices, changing living conditions and establishment of dental care programs. Moreover overall attitudes and behavior of general public have also grown ${ }^{7}$. On the contrary in developing countries incidence of dental caries has increased gradually ${ }^{8}$. It can be attributed to the fact that no dental or oral health care programs are performed in these communities.

Not many studies are there which could provide sufficient data regarding the knowledge, attitudes and behavior of the general population towards oral health care especially in developing countries like Pakistan. Therefore there is dire need to perform a study which can show the general trends of human population in our community towards oral hygiene.

\section{Material and Method:}

A total number of 378 patients were enrolled in this study. The study was performed from January 2016 to June 2018, in Dental Section Allied Hospital, Faisalabad, Fatima Jinnah Hospital, Multan and THQ Sillanwali. All the patients aged 10 to 70 presenting to the out-patient department with the complaint of tooth ache were included in 
this study. Approval for the study was obtained from the Hospital Ethics Committee. Sample size was calculated from the reference study by Muhammad K. Al-Omiri et al ${ }^{10}$. Non probability consecutive type of sampling technique was used to collect the sample size. A questionnaire was developed to gather the information required for the determination of knowledge, attitudes and behavior of the patient towards oral health. The questionnaire comprised of thirty three questions regarding different aspects of oral health care. It involved questions regarding demographic information, knowledge, attitudes and behavior of the patients.

Demographic information included age, gender, education status, occupations, socio-economic status, type of family and religion. For knowledge regarding dental pain questions regarding causes the rapid dental decay, source of oral health knowledge and frequency of visit to dentist were asked. Similarly for attitude regarding dental pain treatment questions regarding, duration of pain, relieving factor, aggravating factor, type of pain, intensity, associated symptoms, time when pain started, time period between $1^{\text {st }}$ incidence of pain and $2^{\text {nd }}$ incidence of pain, approach in case of pain and any habit. Practicing of oral care was judged by asking question about methods of cleaning teeth, frequency of brushing, technique of brushing, change of brush, time of brushing, reason to brush the teeth, reason for last dental visit, approach if there is dental decay, brushing habits of family members, home remedies and medications. All the data thus calculated was subjected to statistical analysis. Computer software SPSS version 23 was used to analyze the data. Frequency and percentage was calculated for quantitative variables while mean and standard deviation was calculated for qualitative variables.

\section{Results:}

Three hundred and seventy eight patients were included in this study, both genders. Gender distribution revealed as $n=257(68 \%)$ males and $n=121(32 \%)$ females. The mean age of the patients was $26.14 \pm 3.15$ years. There were $\mathrm{n}=196(51.9 \%)$ patients literate and $\mathrm{n}=182(48.1 \%)$ were illiterate. Occupations distribution observed as $\mathrm{n}=47$ $(12.4 \%)$ employee, $n=61(16.1 \%)$ worker, $n=121(32 \%)$ student, and $n=149(39.4 \%)$ house wives. Socio-economic status noted as $n=92(24.3 \%)$ upper class, $n=125(33.1 \%)$ middle class and $n=161(42.6 \%)$ lower class. $n=250$ $(66.1 \%)$ were living in joint family and $n=128$ (33.9\%) were nuclear family. Whereas, $n=364(96.3 \%)$ Muslims were and $n=14(3.7 \%)$ were non-Muslims. (Table I).

Knowledge regarding dental pain was assessed from the patients from different questions. It was seen that majority of the patients were unfamiliar about the knowledge regarding dental pain table II. Attitude towards dental pain treatment of the patients were shown in table III. It was observed that majority of the patients did not take proper remedy for dental pain.

Regarding to oral care, $n=213(56.3 \%)$ used tooth paste, $n=260(68.8 \%)$ patients brush once a day, $n=178(47.1 \%)$ used vertical technique for brushing. $n=138(36.5 \%)$ changed their brush every six months while $n=60(15.9 \%)$ changed their brush after one year. $n=189(50 \%)$ patients brush their teeth in morning, $n=166(43.9 \%)$ brush their teeth for cleaning purpose. $\mathrm{n}=144(38.1 \%)$ visited to dentist when they felt pain. $\mathrm{n}=170(45 \%)$ ignore, $\mathrm{n}=98$ $(25.9 \%)$ go to the dentist and $n=110(29.1 \%)$ use home remedies when they felt dental decay. $n=239(63.2 \%)$ patients' family members brush their teeth regularly. Self-medication was observed as $n=269(71.2 \%)$. Distribution of home remedies is shown in table IV. 
Table I

\section{Demographic variables}

\begin{tabular}{|c|c|c|}
\hline Variable & Number & Percentage \\
\hline \multicolumn{3}{|l|}{ Age (years) } \\
\hline Mean \pm S.D & \multicolumn{2}{|c|}{$26.14 \pm 3.15$} \\
\hline \multicolumn{3}{|l|}{ Gender } \\
\hline Male & 257 & 68 \\
\hline Female & 121 & 32 \\
\hline \multicolumn{3}{|l|}{ Education status } \\
\hline Literate & 196 & 51.9 \\
\hline Illiterate & 182 & 48.1 \\
\hline \multicolumn{3}{|l|}{ Occupations } \\
\hline Employee & 47 & 12.4 \\
\hline Worker & 61 & 16.1 \\
\hline Student & 121 & 32 \\
\hline House wife & 149 & 39.4 \\
\hline \multicolumn{3}{|c|}{ Socio-economic status } \\
\hline Upper class & 92 & 24.3 \\
\hline Middle class & 125 & 33.1 \\
\hline Lower class & 161 & 42.6 \\
\hline \multicolumn{3}{|l|}{ Type of family } \\
\hline Joint & 250 & 66.1 \\
\hline Nuclear & 128 & 33.9 \\
\hline \multicolumn{3}{|l|}{ Religion } \\
\hline Muslim & 364 & 96.3 \\
\hline Non-Muslim & 14 & 3.7 \\
\hline
\end{tabular}


Table II

\section{Knowledge Regarding Dental Pain}

\begin{tabular}{|c|c|c|}
\hline Variable & Number & Percentage \\
\hline \multicolumn{3}{|c|}{ What causes the rapid dental decay } \\
\hline Decreased brushing frequency & 227 & 60.1 \\
\hline Increased sugar intake & 75 & 19.8 \\
\hline Cold drink consumption & 76 & 20.1 \\
\hline \multicolumn{3}{|l|}{ Source of oral health knowledge } \\
\hline Media source & 42 & 11.1 \\
\hline Family members & 151 & 39.9 \\
\hline Friends & 57 & 15.1 \\
\hline Teachers & 105 & 27.8 \\
\hline Others & 23 & 6.1 \\
\hline \multicolumn{3}{|l|}{ If gums bleed what you do } \\
\hline Stop brushing & 140 & 37.0 \\
\hline Increase brushing & 76 & 20.1 \\
\hline Go to dentist & 36 & 9.5 \\
\hline Nothing & 126 & 33.3 \\
\hline \multicolumn{3}{|c|}{ Is oral health related to systemic health } \\
\hline Yes & 292 & 77.2 \\
\hline No & 86 & 22.8 \\
\hline \multicolumn{3}{|l|}{ Frequency of visit to dentist } \\
\hline Every 6 months & 18 & 4.8 \\
\hline After a year & 95 & 25.1 \\
\hline Never & 265 & 70.1 \\
\hline \multicolumn{3}{|c|}{ Is it essential to visit dentist every 6 months } \\
\hline Yes & 245 & 64.8 \\
\hline No & 133 & 35.2 \\
\hline
\end{tabular}

Table III

Attitude Regarding Dental Pain Treatment

\begin{tabular}{|c|c|c|}
\hline Variable & Number & Percentage \\
\hline \multicolumn{3}{|l|}{ Duration of pain } \\
\hline 5 minutes & 45 & 11.9 \\
\hline$>$ mminutes & 49 & 13.0 \\
\hline 20 minutes & 40 & 10.6 \\
\hline 30 minutes & 52 & 13.8 \\
\hline Continuous pain & 192 & 50.8 \\
\hline \multicolumn{3}{|l|}{ Relieving factor } \\
\hline Cold water gargles & 19 & 5.0 \\
\hline Pain killers & 206 & 54.5 \\
\hline Salt water gargles & 55 & 14.6 \\
\hline Tooth paste & 98 & 25.9 \\
\hline \multicolumn{3}{|l|}{ Aggravating factor } \\
\hline Mastication & 22 & 5.8 \\
\hline Sweets & 116 & 30.7 \\
\hline Hot and cold things & 151 & 39.9 \\
\hline Food impaction & 28 & 7.4 \\
\hline Sour things & 61 & 16.1 \\
\hline
\end{tabular}




\begin{tabular}{|c|c|c|}
\hline Spontaneous & 92 & 24.3 \\
\hline Stimulated & 70 & 18.5 \\
\hline Referred & 93 & 24.6 \\
\hline Non-referred & 123 & 32.5 \\
\hline \multicolumn{3}{|l|}{ Intensity } \\
\hline Mild & 90 & 23.8 \\
\hline Moderate & 133 & 35.2 \\
\hline Severe & 155 & 41.0 \\
\hline \multicolumn{3}{|l|}{ Associated with } \\
\hline Swelling & 163 & 43.1 \\
\hline Fever & 37 & 9.8 \\
\hline Sinus & 24 & 6.3 \\
\hline Nothing & 154 & 40.7 \\
\hline \multicolumn{3}{|l|}{ Sensitivity to } \\
\hline Cold & 216 & 57.1 \\
\hline Hot & 55 & 14.6 \\
\hline Sweet & 76 & 20.1 \\
\hline Sour & 31 & 8.2 \\
\hline \multicolumn{3}{|c|}{ When did the pain started recently } \\
\hline Within one week & 254 & 67.2 \\
\hline Before one week & 52 & 13.8 \\
\hline Before 2 weeks & 54 & 14.3 \\
\hline Before 1 month & 18 & 4.8 \\
\hline \multicolumn{3}{|c|}{ Time period between $1^{\text {st }}$ incidence of pain and $2^{\text {nd }}$ incidence of pain } \\
\hline 1 week & 53 & 14.0 \\
\hline 2 weeks & 95 & 25.1 \\
\hline More than 2 weeks & 113 & 29.9 \\
\hline 1 month & 117 & 31.0 \\
\hline \multicolumn{3}{|c|}{ What was your approach in case of pain } \\
\hline Good doctor & 11 & 2.9 \\
\hline Private clinic & 26 & 6.9 \\
\hline Brushing regularly & 128 & 33.9 \\
\hline Hakeem & 8 & 2.1 \\
\hline Quack & 112 & 29.6 \\
\hline Home remedy & 78 & 20.6 \\
\hline Dam & 4 & 1.1 \\
\hline Homeopathy & 11 & 2.9 \\
\hline \multicolumn{3}{|c|}{ Why did you delay seeking consultation } \\
\hline Busy life & 19 & 5.0 \\
\hline Mild tolerable pain & 95 & 25.1 \\
\hline Non availability of conveyance & 58 & 15.3 \\
\hline Costly treatment & 71 & 18.8 \\
\hline Pain is subsiding & 38 & 10.1 \\
\hline Hospital faraway & 55 & 14.6 \\
\hline Dental treatment fear & 42 & 11.1 \\
\hline \multicolumn{3}{|l|}{ Do you have habit of } \\
\hline Pan\chaliya & 51 & 13.5 \\
\hline Niswar & 26 & 6.9 \\
\hline Smoking & 76 & 20.1 \\
\hline Carbonated drinks & 144 & 38.1 \\
\hline Milk & 67 & 17.7 \\
\hline None & 14 & 3.7 \\
\hline
\end{tabular}


Table IV

\section{Practicing of Oral Care}

\begin{tabular}{|c|c|c|}
\hline Variable & Number & Percentage \\
\hline \multicolumn{3}{|l|}{ Methods of cleaning teeth } \\
\hline Tooth paste & 213 & 56.3 \\
\hline Dentonic powder & 34 & 9.0 \\
\hline Miswak & 61 & 16.1 \\
\hline Mouth wash & 48 & 12.7 \\
\hline Tooth picks & 22 & 5.8 \\
\hline \multicolumn{3}{|l|}{ Frequency of brushing } \\
\hline Twice a day & 46 & 12.2 \\
\hline Thrice a day & 5 & 1.3 \\
\hline Once a day & 260 & 68.8 \\
\hline Do not brush & 67 & 17.7 \\
\hline \multicolumn{3}{|l|}{ Technique of brushing } \\
\hline Horizontal & 170 & 45.0 \\
\hline Vertical & 178 & 47.1 \\
\hline Circular & 30 & 7.9 \\
\hline \multicolumn{3}{|l|}{ Change of brush } \\
\hline Every 3 months & 115 & 30.4 \\
\hline Every 6 months & 138 & 36.5 \\
\hline After a year & 60 & 15.9 \\
\hline When it gets rough & 65 & 17.2 \\
\hline \multicolumn{3}{|l|}{ Time of brushing } \\
\hline In morning & 189 & 50.0 \\
\hline Before breakfast & 13 & 3.4 \\
\hline In evening & 22 & 5.8 \\
\hline Before going to bed & 27 & 7.1 \\
\hline Both evening and morning & 127 & 33.6 \\
\hline \multicolumn{3}{|l|}{ Reason to brush the teeth } \\
\hline Cleaning purpose & 166 & 43.9 \\
\hline Brightening of teeth & 81 & 21.4 \\
\hline To stop bleeding & 24 & 6.3 \\
\hline To stop cavity & 107 & 28.3 \\
\hline \multicolumn{3}{|l|}{ Reason for last dental visit } \\
\hline Extraction & 123 & 32.5 \\
\hline Pain & 144 & 38.1 \\
\hline Filling of cavity & 111 & 29.4 \\
\hline \multicolumn{3}{|c|}{ On seeing dental decay what do you do } \\
\hline Ignore & 170 & 45.0 \\
\hline Go to dentist & 98 & 25.9 \\
\hline Use home remedies & 110 & 29.1 \\
\hline \multicolumn{3}{|c|}{ Do your family members brush their teeth regularly } \\
\hline Yes & 239 & 63.2 \\
\hline No & 139 & 36.8 \\
\hline \multicolumn{3}{|l|}{ What home remedies you use } \\
\hline Clove & 22 & 5.8 \\
\hline Salt water gargles & 25 & 6.6 \\
\hline Honey & 28 & 7.4 \\
\hline Ice water & 32 & 8.5 \\
\hline Tooth paste & 113 & 29.9 \\
\hline Pain killers and antibiotics & 72 & 19.0 \\
\hline Interdental aid & 21 & 5.6 \\
\hline Antibiotics & 33 & 8.7 \\
\hline Pain killers & 32 & 8.5 \\
\hline \multicolumn{3}{|l|}{ Medication } \\
\hline Self & 269 & 71.2 \\
\hline After consulting a doctor & 109 & 28.8 \\
\hline
\end{tabular}




\section{Discussion:}

Numerous factors are responsible for oral hygiene and oral health behaviors in a population. Positive reinforcement and proper informing about the health care regimen improves the compliance of the patients towards the treatment. Non compliance and non adherence to the oral hygiene practices is directly associated with lack of information and motivation. The more the knowledge a patient has regarding the dental care the more will be the possibility of him to seek preventive health care. Knowledge regarding the seriousness of the dental problem and benefits of the treatment available are essential for seeking of health care ${ }^{10,11}$.

The results of our study suggest that overall behavior and attitude of people regarding the practice of oral hygiene and seeking the preventive health care in case of any complaint is very unsatisfactory. A large number of the patients who presented at the out-patient department were illiterate and belonged to poor socioeconomic class of the society. In previous studies poor attitudes and behavior have been attributed to the lack of oral health education programs ${ }^{12,13}$. The problem in our community is not very different health education programs are conducted in very less amount which is why overall oral health knowledge, behavior and attitudes of the patient are very poor. Previous studies also suggest that in order to improve the oral health conditions among the children and adults, dependency of patients on health personnel should be decreased and patients should be encouraged to be responsible for their own health ${ }^{14}$.

Similarly preventive approach should be emphasized over curative approach by improving the lifestyles especially

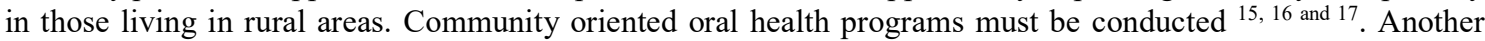
study in India indicated that overall behavior, attitudes and knowledge of oral health care among children and their parents needs improvements as results were not satisfactory enough. This requires health educations as well as improvement in socioeconomic conditions as these conditions are direct influence on the behavior and attitude of participants of the study ${ }^{18}$.

\section{Conclusion:}

Although majority of the patients had good knowledge about health care but it was not associated with better attitudes, behavior and practicing of healthy habits. It can be suggested that poor socioeconomic conditions of majority of the public and lack of motivation for oral hygiene are the cause of poor behavior, attitude and practicing of dental care.

\section{Conflict of interest:}

There was no conflict of interest.

\section{Funding Source:}

No external funding source was used.

\section{References:}

1- Murray Thomson W. Epidemiology of oral health conditions in older people. Gerodontol. 2014;31(s1):9-16.

2- Gambhir RS, Brar P, Singh G, Sofat A, Kakar H. Utilization of dental care: An Indian outlook. J nat sci biol med. 2013;4(2):292.

3- Vujicic M, Nasseh K, Wall T. Dental care utilization declined for adults, increased for children during the past decade in the United States. Health Policy Resources Center Research Brief. Am Dent Assoc. 2013.

4- Lagerweij MD, van Loveren C. Declining caries trends: are we satisfied?. Curr oral health rep. 2015;2(4):2127.

5- Takeuchi K, Aida J, Kondo K, Osaka K. Social participation and dental health status among older Japanese adults: a population-based cross-sectional study. PloS one. 2013;8(4):e61741. 
6- Umer MF, Farooq U, Shabbir A, Zofeen S, Mujtaba H, Tahir M. PREVALENCE AND ASSOCIATED FACTORS OF DENTAL CARIES, GINGIVITIS, AND CALCULUS DEPOSITS IN SCHOOL CHILDREN OF SARGODHA DISTRICT, PAKISTAN. J Ayub Med Coll Abbottabad. 2016;28(1):152-6.

7- Nakre PD, Harikiran AG. Effectiveness of oral health education programs: A systematic review. J Int Soc Prev Commun Dent. 2013;3(2):103.

8- Dixit LP, Shakya A, Shrestha M, Shrestha A. Dental caries prevalence, oral health knowledge and practice among indigenous Chepang school children of Nepal. BMC oral Health. 2013;13(1):20.

9- Al-Omiri MK, Al-Wahadni AM, Saeed KN. Oral health attitudes, knowledge, and behavior among school children in North Jordan. J dent educ. 2006;70(2):179-87.

10- Mirza KM, Khan AA, Ali MM, Chaudhry S. Oral health knowledge, attitude, and practices and sources of information for diabetic patients in Lahore, Pakistan. Diabetes Care. 2007;30(12):3046-7.

11- Kneckt M. Psychological features characterizing oral health behavior, diabetes self-care health status among IDDM patients. Oulu University Library 2000, 2011.

12- Priya M, Devdas K, Amarlal D, Venkatachalapathy A. Oral health attitudes, knowledge and practice among school children in Chennai, India. J educ Ethic Dent. 2013;3(1):26.

13- Smyth E, Caamaño F, Fernández-Riveiro P. Oral health knowledge, attitudes and practice in 12-year-old schoolchildren. Medicina Oral, Patología Oral y Cirugía Bucal (Internet). 2007;12(8):614-20.

14- Lian CW, Phing TS, Chat CS, Shin BC, Baharuddin LH, Jalil ZB. Oral health knowledge, attitude and practice among secondary school students in Kuching, Sarawak. Arch orofac Sci. 2010;5(1):9-16.

15- Zhu L, Petersen PE, Wang HY, Bian JY, Zhang BX. Oral health knowledge, attitudes and behaviour of adults in China. Int dent j. 2005;55(4):231-41.

16- Zhu L, Petersen PE, Wang HY, Bian JY, Zhang BX. Oral health knowledge, attitudes and behaviour of children and adolescents in China. Int dent j. 2003;53(5):289-98.

17- Varenne B, Petersen PE, Ouattara S. Oral health behaviour of children and adults in urban and rural areas of Burkina Faso, Africa. Int dent j. 2006;56(2):61-70.

18- Mathur A, Gupta T. Oral health attitude knowledge behavior and consent towards dental treatment among school children. J Orofac Res Vol. 2011;1(1). 